\title{
Do Centres of Endemism provide a spatial context for predicting and preserving plant phylogeographic patterns in the Cape Floristic Region, South Africa?
}

\author{
Nicholas C Galuszynski ${ }^{\text {Corresp., }}{ }^{\text {, Alastair J Potts }}{ }^{1}$ \\ ${ }^{1}$ Botany, Nelson Mandela University, Port Elizabeth, Eastern Cape, South Africa \\ Corresponding Author: Nicholas C Galuszynski \\ Email address: nicholas.galuszynski@gmail.com
}

Aim: The evolutionary forces that gave rise to the exceptional plant species richness of the Cape Floristic Region (CFR) have also likely played a role at the intraspecific level (i.e. plant populations) - and thereby generating shared phylogeographic patterns among taxa. Here we test whether plant populations in the CFR exhibit phylogeographic breaks across the boundaries between Centres of Endemism (CoEs). The boundaries between CoEs (derived from the distribution ranges of endemic taxa and currently mapped at a coarse, Quarter Degree Square [QDS] scale) represent a spatial proxy for the evolutionary diversifying drivers acting on plant taxa in the CFR.

Location: The Cape Floristic Region, located along the southern Cape of South Africa.

Methods: Published phylogeographic literature were compiled and spatial patterns of genetic divergence re-analysed to assess the frequency at which CFR plant taxa exhibit phylogeographic breaks either 1 ) across or 2 ) within CoE boundaries. Population pairs from each study were compared across and within CoEs and scored as either exhibiting a phylogeographic break or not.

Results: Phylogeographic breaks in Cape plants were found to occur across the boundaries of CoEs more often than not. Significantly more population pairs exhibited phylogeographic breaks across CoE boundaries ( 506 of the $540, \chi^{2}=886, p<0.001$ ) and fewer breaks within CoEs (94 of $619, \chi^{2}=300, p<$ 0.001 ) than would be expected if there was equal probability of a genetic break occurring across CoE boundaries.

Main conclusions: The evolutionary forces that have produced and maintained the exceptional plant diversity in the CFR appear to have operated at the population level, producing similar patterns of phylogeographic structuring of plant lineages regardless of life history or taxonomy. This tendency for Cape plants to exhibit shared patterns of spatially structured genetic diversity that match the distribution of endemic taxa may assist CFR phylogeographers to streamline sampling efforts and test novel hypotheses pertaining to the distribution of genetic diversity among CFR plant taxa. Additionally, the resolution at which CoEs are mapped should be refined, which may provide a valuable tool for future conservation planning and the development of precautionary guidelines for the translocation of genetic material during species reintroductions and commercial cultivation of Cape endemic crops. Thus, to answer the question "Do Centres of Endemism provide a spatial context for predicting and preserving plant phylogeographic patterns in the Cape Floristic Region, South Africa?" - yes CoEs do appear to be an important tool for Cape phylogeographers. However, the data is limited and more plant phylogeography work is needed in the CFR. 
1 Do Centres of Endemism provide a spatial context for predicting and preserving 2 plant phylogeographic patterns in the Cape Floristic Region, South Africa?

4 Abstract

5 Aim: The evolutionary forces that gave rise to the exceptional plant species richness of the

6 Cape Floristic Region (CFR) have also likely played a role at the intraspecific level (i.e. plant

7 populations) - and thereby generating shared phylogeographic patterns among taxa. Here

8 we test whether plant populations in the CFR exhibit phylogeographic breaks across the

9 boundaries between Centres of Endemism (CoEs). The boundaries between CoEs (derived

10 from the distribution ranges of endemic taxa and currently mapped at a coarse, Quarter

11 Degree Square [QDS] scale) represent a spatial proxy for the evolutionary diversifying

12 drivers acting on plant taxa in the CFR.

13 Location: The Cape Floristic Region, located along the southern Cape of South Africa.

14 Methods: Published phylogeographic literature were compiled and spatial patterns of 15 genetic divergence re-analysed to assess the frequency at which CFR plant taxa exhibit 16 phylogeographic breaks either 1) across or 2) within CoE boundaries. Population pairs 17 from each study were compared across and within CoEs and scored as either exhibiting a 18 phylogeographic break or not.

Results: Phylogeographic breaks in Cape plants were found to occur across the boundaries of CoEs more often than not. Significantly more population pairs exhibited phylogeographic breaks across CoE boundaries (506 of the $540, \chi^{2}=886, p<0.001$ ) and fewer breaks within CoEs (94 of $619, \chi^{2}=300, p<0.001$ ) than would be expected if there was equal probability of a genetic break occurring across CoE boundaries. 
24 Main conclusions: The evolutionary forces that have produced and maintained the

25 exceptional plant diversity in the CFR appear to have operated at the population level,

26 producing similar patterns of phylogeographic structuring of plant lineages regardless of

27 life history or taxonomy. This tendency for Cape plants to exhibit shared patterns of

28 spatially structured genetic diversity that match the distribution of endemic taxa may assist

29 CFR phylogeographers to streamline sampling efforts and test novel hypotheses pertaining

30 to the distribution of genetic diversity among CFR plant taxa. Additionally, the resolution at

31 which CoEs are mapped should be refined, which may provide a valuable tool for future

32 conservation planning and the development of precautionary guidelines for the

33 translocation of genetic material during species reintroductions and commercial

34 cultivation of Cape endemic crops. Thus, to answer the question "Do Centres of Endemism

35 provide a spatial context for predicting and preserving plant phylogeographic patterns in

36 the Cape Floristic Region, South Africa?" - yes CoEs do appear to be an important tool for

37 Cape phylogeographers. However, data is limited and more plant phylogeography work is

38 needed in the CFR.

52

\section{Introduction}

Understanding spatial patterns of biodiversity is necessary to protect ecosystems, biotic communities, and species of high conservation importance. Unfortunately, the underlying patterns of intraspecific genetic diversity are rarely given equal attention (Coates et al., 2018). Relying on species, in some cases sub-species, as the primary unit for conservation efforts, assumes species are largely homogeneous entities. However, species represent a continuum of adaptive and neutral processes operating across populations (Stapledon, 1928; Turesson, 2010; Vance and Kucera, 1960). Phylogeographic studies of Cape plant taxa have revealed the tendency for populations to exhibit genetic structuring over relatively short geographic distances (Britton et al., 2014; Caujapé-Castells et al., 2002; Galuszynski and Potts, 2020a; Lexer et al., 2014; Malgas et al., 2010; Pirie et al., 2017; Potts et al. 2013; Prunier et al., 2017), suggesting that steep ecological gradients are sufficient barriers to dispersal in the Cape Floristic Region (CFR) to drive genetic differentiation amongst populations. However, intraspecific genetic variation is challenging to integrate into conservation planning in the CFR due to the expense, expertise and time involved in generating such data.

The CFR, located on the southern tip of southern Africa, is a winter rainfall region with exceptional plant species richness and endemism (Goldblatt and Manning, 2002). Many of the endemic species have particularly small ranges, making them especially susceptible to extinction (Helme and Trinder-Smith, 2006; McDonald and Cowling, 1995; Rebelo et al., 2011; Trinder-Smith et al., 1996). Focussing on preserving the processes that maintain these local endemics, systematic conservation planning has identified the need to protect the large scale processes that have shaped the evolutionary history of the regions biota (Cowling et al., 2003; Pressey et al., 2003; Rouget et al., 2003). However, with limited knowledge of the spatial patterns and extent of intraspecific genetic variation within species of an already diverse flora, this level of biodiversity remains largely under- 
65

66

67

68

69

70

71

72

73

74

75

76

77

78

79

80

81

82

83

84

85

86

87

88

89

90

91

92

93

94

95

96

97

98

99

100

101

102

103

104

105

106

represented in CFR conservation strategies. This issue comes to the fore when dealing with processes that involve redistributing genetic material for commercial production or rehabilitation efforts - potentially compromising the genetic integrity of local populations (Hufford and Mazer, 2003; Laikre et al., 2010; Potts, 2017).

Recent studies describing phylogeographic structuring of CFR plants highlight the importance of integrating intraspecific genetic variation into the conservation planning of the region. Work on core Cape clades (sensu Linder, 2003) has consistently detected phylogenetic structuring, with intraspecific divergence occurring over small spatial scales: Erica (Segarra-Moragues and Ojeda, 2010; Ojeda et al., 2015; Van der Niet et al., 2013), Protea (Prunier et al., 2017; Prunier and Holsinger, 2010), Restio (Lexer et al., 2014), and Tetraria (Britton et al., 2014). Furthermore, in the cases of the widespread Protea repens (L.) L. (Proteaceae) (Prunier et al., 2017) and Restio capensis (L.) H.P.Linder and C.R.Hardy (Restionaceae) (Lexer et al., 2014), environmental shifts appear to be more important for isolating populations than geographic distance. These studies also commented on the transition between phytogeographic zones (Goldblatt and Manning, 2002) as an important predictor of environmental transitions - highlighting the potentially important linkages between phytogeography and phylogeography.

Assuming that a regional biota has (largely) experienced the same broad evolutionary pressures (geological and climate variability), patterns of phylogeographic structuring are likely to be shared among species (however, co-occurring species can exhibit discordant phylogeographic patterns, Soltis et al., 2006). Applying multi-species data to identify regional patterns of genetic divergence has proven particularly valuable in exploring the role of Pleistocene climate oscillations in shaping species distribution patterns elsewhere in the world (e.g. Byrne, 2008; Hewitt, 2008; Sork et al., 2016; Turchetto-Zolet et al., 2012) and has facilitated conservation planning for biodiverse floristic regions (Byrne, 2007). Unfortunately, phylogeographic studies are numerically and spatially limited in the CFR, often focusing on a small spatial extent as CFR taxa tend to have restricted geographic ranges. Thus, there is often little overlap in sampling domain among studies, hindering any attempts to conduct comparative phylogeography in the CFR. However, the diversity of the system has attracted extensive taxonomic work (Treurnicht et al., 2017), producing remarkable species distribution records. We test whether phytogeographic boundaries can be used to predict the positions of phylogeographic breaks.

Here we used the core CFR Centres of Endemism (CoEs) of Bradshaw et al. (2015), coupled with published phylogeographic studies, to test how often plant populations exhibit phylogeographic breaks across the boundaries between these CoEs. . While alternative phytogeographic zones are available (Goldblatt and Manning, 2002; Weimarck, 1941), they lack objective and reproducible methods (Bradshaw et al., 2015). In contrast, the CoEs were identified using numerical methods, based on the co-distribution of CFR endemic taxa. Briefly, the approach used in (Bradshaw et al., 2015) comprised the following: the distributions of CFR endemic taxa, mapped at Quarter Degree Squares (QDS), were evaluated and all widespread species and/or species whose distribution were limited to single QDS were downweighted; and, taxon similarity among cells was then measured and 
107 clustered to produce spatially defined endemic communities, CoEs. While the CoEs share 108 spatial congruence with the earlier (subjective) maps (Figure 1), CoEs appear to have a 109 finer resolution with more centres and sub-centres. More importantly, much of the 110 increased resolution of the CoEs is concentrated in the western CFR, which consists of a 111 mosaic of multiple small CoEs while the eastern CFR is dominated by two large CoEs (CoEs 1124 [blue] and 5 [green] in Figure 1).

113 This pattern of decreased size and increased abundance of CoEs in the western CFR reflects 114 the distribution of species richness in the Cape. The number of localised endemic taxa and 115 species diversity is greatest in the west and gradually decreases as one moves east; this 116 trend is referred to as Levyn's Law (after the renowned Cape botanist who first described 117 this pattern, Margeret Levyn. Cowling et al., 2017). This gradient of floral diversity has been 118 ascribed to differences in climate history between the western and eastern CFR. The stable 119 climate history of the western CFR would have promoted species accumulation through 120 reduced extinction events (Cowling et al., 2009; Cowling et al., 2017; Cowling and Lombard, 121 2002), with speciation occurring over short distances along niche axes (Ellis et al., 2014). In 122 the eastern CFR, however, Pleistocene climate change disrupted vegetation distributions 123 (Chase and Meadows, 2007; Huntley et al., 2016) resulting in possible extinction of local 124 endemics (Cowling and Lombard, 2002), homogenising the Cape floral communities in this 125 sub-region, and thus giving rise to fewer, large CoEs.

126

127

128

129

130

131

132

133

134

135

136

137

138

139

140

141

142

143

144

145

146

147

148
The overall stable evolutionary context in the CFR has possibly limited shifts in species ranges, thereby preventing gene flow among populations and promoting speciation (Cowling et al., 2015). As this context has not changed, populations are likely to become isolated over short distances and intraspecific genetic divergence may follow the distribution of endemic taxa. We therefore hypothesise that, intraspecific genetic divergence will mirror the distribution of CFR endemic taxa (i.e. phylogeographic breaks occur across the boundaries between CoEs more often than within CoEs), which represent the ultimate consequence of genetic isolation over a short spatial scale: speciation. Ideally, sample distributions from a large number of studies with high density population sampling would be explored in the context of CoEs mapped at a scale finer than QDS, but such data is currently not available for the CFR. Nevertheless, by developing a simple rule set for assigning populations to CoEs and relying on published molecular analyses to detect phylogeographic breaks between population pairs, we tested the extent to which phylogeographic breaks mirror CoE boundaries in the CFR.

The insights presented here should facilitate future investigations into intraspecific genetic variation, wild genetic resource management, and conservation planning in the CFR (Fraser and Bernatchez, 2001; Thakur et al., 2018). Furthermore, this study hopes to encourage Cape phylogeographers to design studies that test hypotheses regarding the spatial patterns of genetic diversity and the processes that maintain the exceptional diversity of this region and, aid in setting a precautionary guideline for the sampling and redistribution of genetic diversity for ex situ conservation, rehabilitation initiatives, and commercial cultivation (Hufford and Mazer, 2003; Laikre et al., 2010; Potts, 2017; Schipmann et al., 2005). 


\section{Methods and Materials}

\section{Comparing the geographic distribution of genetic lineages with respect to CoEs}

151 To test whether there is a significant pattern for Cape floral lineages to exhibit

152 phylogeographic breaks across the boundaries of CoEs (Bradshaw et al., 2015), all peer

153 reviewed, published studies found using the search terms "population structure",

154 "population differentiation", "genetic structure", "phylogeography", "geographic

155 divergence", "population divergence", and "adaptive divergence" of CFR plant taxa were

156 compiled by initially consulting reviews of Cape phylogeography (Lexer et al., 2013; Tolley

157 et al., 2014) followed by searching online databases using the Google scholar search engine

158 (https://scholar.google.co.za/). A broad definition of phylogeography was adopted at this

159 stage due to the general lack of intraspecific phylogeographic literature focusing on CFR

160 plant taxa and any study including a phylogenetic analysis in relation to a mapped

161 geographic distribution of the samples analysed was included (i.e., species-level

162 phylogenetic studies). Thus, a preliminary total of 17 studies covering intra- and

163 interspecific phylogeographic investigations were identified. Five of the studies were,

164 however, excluded from the investigation, three due to potential data reproducibility issues

165 of RAPD and ISSR molecular markers (Bergh et al., 2007; Heelemann et al., 2013; Tansley

166 and Brown, 2000); another due to the same data set being used in multiple publications

167 (Segarra-Moragues and Ojeda, 2010; Ojeda et al., 2015); and a third due to lack of

168 information on the geographic location of samples (Latimer et al., 2009). The remaining 12

169 studies were used in the CoE analysis (Table 1) - these provided a total of 179

170 populations for the between versus within CoE population pair comparisons (raw

171 population scoring data is available online at doi:10.6084/m9.figshare.11370468.v1) and included

172 a range of molecular marker types (Microsatellite, Sanger Sequencing, Next-Generation

173 Sequencing and, AFLP markers, summarized in Table 1).

174 To test whether genetic divergence occurs across the CoEs, each study's sample

175 distribution map was overlaid with the CoEs and each population assigned to a centre

176 using QGIS [3.2.2] (Lacaze et al., 2018). In cases where populations occurring near the

177 boundaries between CoEs were challenging to assign to either CoE, an approach that

178 promotes a null-hypothesis (i.e. phylogeographic breaks do not occur across CoE

179 boundaries) was adopted. These populations were marked as having an uncertain CoE

180 membership and (unless genetically unique among all the populations in either possible

181 CoEs) were considered to not exhibit a phylogeographic break across CoEs. This increased

182 the tendency to detect cases of no phylogeographic break across CoE boundaries.

183 From the phylogenetic or phylogeographic analyses reported in each study, it was

184 determined whether population pairs exhibited genetic divergence. Populations were

185 assigned to a genetic group based on membership to a clade or sub-clade as reported in

186 their respective studies. Population pairs occurring across adjacent $\mathrm{CoE}$ boundaries were

187 then evaluated to determine if they belonged to the same, or different genetic groups. Each

188 population pair was scored as either: a) representing an phylogeographic break across the

189 CoE boundary (hereafter referred to as a "CoE phylogeographic break"), or b) representing 
190 no phylogeographic break across the CoE boundary (hereafter referred to as "inter-CoE

191 homogeneity"). In addition, genetic divergence between population pairs occurring within

192 CoEs was examined for each study using the same approach, with each possible population

193 pair within a CoE scored as either exhibiting a phylogeographic break or homogeneity. The

194 sample distributions of a subset of the studies used to explore phylogeographic breaks

195 across CoEs are shown in Figure 2, providing examples of populations marked as

196 exhibiting: no phylogeographic break across CoE boundaries, uncertain CoE membership,

197 or within CoE divergence.

198

199

200

201

202

203

204

205

206

207

208

209

210

211

212

213

214

215

216

217

218

219

220

221

222

223

224

225

Chi-squared tests with simulated p-value based on 10000 replicates were used to determine whether the final population scoring deviated from random assignment with equal probability of population pairs exhibiting a CoE phylogenetic break or homogeneity. Tests were performed using the base package in $R$ [v3.5.1] (R Core Team 2018).

\section{Results:}

The final data set consisted of 540 population pairs compared across a total of 33 boundaries between adjacent CoEs. Eight genera were included in the analysis, with an average of $10(\mathrm{SD}=9$, range $=1-25) \mathrm{CoE}$ boundaries compared per genus. The number of population pairs compared across adjacent CoEs ranged from one (six studies) to seven (two studies) with an average of $3(\mathrm{SD}=2$, range $=1-17) \mathrm{CoE}$ boundaries compared per study. Sampling in five of the studies included in the CoE analysis were limited to the western CFR, while only one was limited to the eastern CFR and the remainders sampled across the western and eastern CFR.

More populations pairs (506 of 540) exhibited phylogenetic breaks across CoE boundaries that would be expected if there was equal probability of assignment $\left(x^{2}=886, p<0.001\right)$. Eight populations exhibited CoE uncertainty and were subsequently combined with the populations pairs that exhibited inter-CoE homogeneity, resulting in a total of 34 population pairs exhibiting inter-CoE homogeneity. The number of cases of phylogeographic breaks, uncertainty of $\mathrm{CoE}$ membership and inter-CoE homogeneity for each of the CoE boundaries examined are shown in Figure 3.

While relatively few population comparisons exhibited inter-CoE homogeneity, it is important to note that many of the cases of homogeneity involve the Hexriver Mountain Centre (CoE 14), which Bradshaw et al. (2015) identified as a possible transitional zones between CoEs. The remaining cases of inter-CoE homogeneity represent isolated cases.

Within CoE divergence comparisons were conducted on a total of 619 population pairs occurring within 11 CoEs. Of these, 525 exhibited intra-CoE homogeneity (i.e. 94 pairs contained intra-CoE divergence), more than expected than if there was equal probability of assignment $\left(x^{2}=300, p<0.001\right)$ and shown in Figure 3 inset. 
226 Thus, inter-population divergence was detected in $93.7 \%(n=540)$ of paired populations

227 found on either side of a CoE boundary whereas only $15.2 \%(n=619)$ were found within

228 CoEs.

\section{Discussion}

230 The results of this study support the hypothesis that the evolutionary forces that have

231 shaped the distribution of endemic plant taxa in the CFR are also operating at the intra-

232 specific level, potentially generating shared patterns of phylogeographic structuring among

233 plant taxa in the CFR. A significant trend was detected for population pairs to exhibit

234 phylogeographic breaks across CoE boundaries, while population pairs within CoEs

235 exhibited significantly more genetic homogeneity. These results should, however, be

236 viewed as preliminary insights into general CFR phylogeographic trends. The incomplete

237 phylogeographic sampling across the CFR, and a coarse QDS scale mapping of the CoEs

238 used make this study a proof of concept, which provides a novel hypothesis to be tested

239 using more refined data sets by future workers.

240 Nonetheless, reducing complex species distributions to spatially distinct geographic units, 241 or phytogeographic zones, appears to be particularly useful in species rich areas (Edler et

242 al., 2016), where generating data for a representative number of individual species may be

243 time consuming and financially restrictive. Defining phytogeographic zones based on

244 evolutionary processes unique to the landscape under investigation, such as distribution of

245 endemic taxa in the CFR, results in the boundaries between the defined zones possibly

246 being representative of local evolutionary drivers (Bradshaw et al., 2015). If this is the case, 247 as our results suggest, CoEs may provide a valuable resource for phylogeographic research, 248 conservation planning and wild genetic resource management in the CFR. Below we briefly

249 discuss the potential role CoEs may play in facilitating the advancement of these fields.

\section{The potential role of CoEs in future research}

251 Fundamental to any successful molecular ecological study is adequate sample collection

252 across the target species' range and within populations. Furthermore, strategic sampling of

253 genetic variation across a species' range offers the opportunity for specific hypotheses to

254 be statistically tested (Morando et al., 2003). However, sampling design has proven to be a

255 challenge for phylogeographers and is often highly variable within and across studies

256 (Gutiérrez-García and Vázquez-Domínguez, 2011). This is evident in the CFR, with the

257 average minimum and maximum number of individuals sampled per population being 8

$258(\mathrm{SD}=8)$ and $21(\mathrm{SD}=16)$, respectively (Table 1).

259 This haphazard sampling is often unavoidable in the context of the CFR, where frequent

260 fires may rapidly reduce populations to a few individuals (Galuszynski and Potts, 2020a)

261 and populations may be restricted to inaccessible mountain sites (McDonald and Cowling,

262 1995; Schutte et al., 1995). However, the realization that the boundaries between CoEs may

263 predict phylogeographic breaks among populations in the CFR, presents an opportunity to 
264 explore intraspecific genetic variation with targeted sampling. Sampling strategies can be 265 planned around this information to either maximise the amount of intraspecific genetic 266 variation detected (i.e. sample populations from different CoEs and sub-CoEs), or explore 267 specific phylogeographic and evolutionary hypotheses (e.g. sample transects across CoE 268 boundaries, or explore adaptive divergence of populations sampled from different CoEs).

269 While these suggestions act only to highlight possible applications of CoEs in molecular

270

271

272

273

274

275

276 ecology and phylogeography in the CFR, the first step towards integrating CoEs into novel molecular research should be the remapping of CoEs at finer resolution. Bradshaw et al. (2015) recognized the limitations of a coarse scale at which the CoEs were mapped, at times resulting in the merging of lowland and mountain habitats into single CoEs and a number of poorly resolved centres. The inclusion of finer scaled distributional data in future $\mathrm{CoE}$ mapping may help overcome this issue of resolution and facilitate the integration of CoEs into other spatial planning and management activities in the CFR.

\section{Implications for conservation planning}

The current regional conservation plan in the CFR (Cape Action Plan for People and the Environment, CAPE) was developed in 2003 (Cowling and Pressey 2003), prior to the publication of any of the phylogeographic studies included in this study (Table 1). Applying a systematic conservation planning approach to selecting sites of high conservation value, CAPE relied predominantly on environmental features, mapped as Broad Habitat Units (Cowling and Heijnis, 2001), and the distribution of vertebrates and Proteaceae for generating measures of irreplaceability (Cowling et al., 2003). In this context, irreplaceability refers to the potential contribution of a site to achieving a predetermined conservation goal, or alternatively, the extent to which achieving said conservation goal is compromised if a site is lost (Pressey et al., 1994). The irreplaceability of BHUs can therefore be viewed as the currency with which conservation success is ultimately measured. While the BHUs used to develop CAPE were conceived with the preservation of local evolutionary processes in mind (Cowling and Heijnis, 2001), environmental data was used as a proxy to represent these processes and the BHUs share little spatial congruence with the CoEs of (Bradshaw et al., 2015). Consequently, current conservation targets could be failing to adequately represent intraspecific genetic diversity. Phylogeographic data should therefore be included in future conservation planning in the CFR.

295

296

297

298

299

300

301

302

303

304

The description of conservation priorities using insights gained from phylogeographic analysis has been applied to biodiverse regions elsewhere in the world. These include setting conservation priorities for the: mammal fauna of the Amazon (Da Silva and Patton, 1998); lizard fauna of northern Australia (Rosauer et al., 2016); and the floras of south western Australia (Byrne, 2007), California (Calsbeek et al., 2003), and the Mediterranean basin (Médail and Baumel, 2018). However, the phylogeographic studies conducted in these regions, and subsequently used to define conservation targets, were done on species with sufficient range overlap to allow for the detection of shared patterns of genetic structuring. Unfortunately, with only four phylogeographic studies conducted on widespread CFR taxa and most studies limited to species endemic to the West Coast and 
305 immediate surrounding areas (Figure 2, Table 1), there are still areas with no available 306 phylogeographic information (predominantly in the north werstern and eastern CFR). Thus 307 CoE boundaries may be suitable surrogates for general phylogeographic data in aiding 308 conservation planning until more phylogeographic research is conducted in the CFR, 309 providing a readily available, precautionary and cost effective means of accounting for 310 intraspecific genetic diversity in future conservation planning in the CFR.

\section{Spatial limits to translocation}

312 In addition to delimiting areas for conserving extant habitat, due to the high numbers of 313 locally endemic plant taxa (8900 endemic species occur in the broader Cape area, 314 Goldblatt and Manning, 2002), achieving conservation targets may require the 315 reintroduction of species into previously degraded habitats (Cowan and Anderson, 2014; 316 Rebelo et al., 2011; Waller et al., 2015; Waller et al., 2016) or translocations into novel 317 habitat (Milton et al., 1999). Furthermore, rises in consumer consciousness have increased 318 the demand for natural products, which in turn has resulted in increased cultivation of wild crop species as a means to curb plant population decline associated with wild harvesting (Canter et al., 2005; Lubbe and Verpoorte, 2011; Schipmann et al., 2005). Unfortunately, the underlying levels of genetic diversity and structuring have rarely been considered during translocation activities, and may expose local populations to foreign genetic material, possibly disrupting local genetic diversity patterns (Laikre et al., 2010; McKay et al., 2005).

325

326

327

328

329

330

331

332

333

334

With no general guidelines in place to direct the redistribution of genetic material in the CFR, it is unlikely that the potential for geographically structured genetic lineages is considered during translocation activities. However, with investigations into genetic issues associated with the translocation of endemic plants only recently emerging in the literature (Bello et al., 2018; Galuszynski, in review; Johnson, 2018; Macqueen and Potts, 2018; Malgas et al., 2010; Mayonde et al., 2015; Potts, 2017), it is clear that more work is required to better describe and protect wild genetic diversity in the CFR. Centres of Endemism offer a suitable proxy to develop precautionary limits to the redistribution of genetic material and design sampling strategies for describing the levels of wild genetic diversity of CFR taxa for the development of genetic resource management plans.

\section{Conclusions}

336

337

338

339

340

341

342

343

The data sets used in this study were not developed with the intention of answering the questions posed here, and there is great potential to refine this work in future studies. Finer resolution mapping units should be used to generate CoEs. Be it with environmental layers that represent putative barriers to dispersal, modeled distributions of endemic plant taxa, which in itself includes environmental data, or more fine resolution locality data. Regardless, more refined edges between CoEs should be developed to better reflect natural boundaries between species distributions and evolutionary processes. From these refined CoEs, hypothesis-driven sampling of populations can be conducted to test for 
344 phylogeographic breaks across CoEs, facilitating explorations into the evolutionary 345 processes that have generated the observed patterns of phylogeographic structuring and 346 diversity in the CFR flora. Additionally, this study highlights the lack of available 347 phylogeographic work in the CFR. Future studies should focus on exploring novel genera and widespread taxa, which will help to fill the current gaps in our phylogeographic knowledge of Cape plants.

350

351

352

353

354

355

356

357

358

359

Despite the limited data available for the current study, the overwhelming tendency for phylogeographic breaks to occur across CoE boundaries highlights an important aspect of diversity in the CFR - intraspecific genetic divergence has likely been driven by the same forces that have generated the exceptional floristic diversity of this region. Centres of Endemism do, therefore, provide a spatial context for predicting and preserving plant phylogeographic patterns in the CFR. These findings highlight the potential value of CoEs for: developing phylogeographic research, aiding future conservation planning, and sampling wild genetic resources. Furthermore, policy should ensure that CoEs be adopted as precautionary spatial limits for the translocation of genetic lineages for rehabilitation and commercial cultivation, until data specific to the species concerned is made available.

\section{References}

Bello, A., Stirton, C.H., Chimphango, S.B.M., Muasya, A.M., 2018. Morphological evidence for introgressive hybridization in the genus Psoralea L. (Psoraleeae, Fabaceae). South African Journal of Botany 118, 321-328. https://doi.org/10.1016/j.sajb.2018.02.407

Bergh, N.G., Hedderson, T.A., Linder, H.P., Bond, W.J., 2007. Spatial pattern of genetic variation in Elytropappus rhinocerotis (Asteraceae) from the Cape provinces of South Africa. South African Journal of Botany 73, 279-280.

https://doi.org/10.1016/j.sajb.2007.02.019

Bradshaw, P.L., Colville, J.F., Linder, H.P., 2015. Optimising regionalisation techniques: identifying Centres of Endemism in the extraordinarily endemic-rich Cape Floristic Region. PLoS One 10, e0132538. https://doi.org/10.1371/journal.pone.0132538

Britton, M.N., Hedderson, T.A., Verboom, G.A., 2014. Topography as a driver of cryptic speciation in the high-elevation cape sedge Tetraria triangularis (Boeck.) C. B. Clarke (Cyperaceae: Schoeneae). Molecular Phylogenetics and Evolution 77, 96-109.

https://doi.org/10.1016/j.ympev.2014.03.024

Byrne, M., 2008. Evidence for multiple refugia at different time scales during Pleistocene climatic oscillations in southern Australia inferred from phylogeography. Quaternary Science Reviews 27, 2576-2585. https://doi.org/10.1016/j.quascirev.2008.08.032 
378 Byrne, M., 2007. Phylogeography provides an evolutionary context for the conservation of a 379 diverse and ancient flora. Australian Journal of Botany 55, 316.

380 https://doi.org/10.1071/bt06072

381 Calsbeek, R., Thompson, J.N., Richardson, J.E., 2003. Patterns of molecular evolution and

382 diversification in a biodiversity hotspot: the California Floristic Province. Molecular

383 Ecology 12, 1021-1029. https://doi.org/10.1046/j.1365-294x.2003.01794.x

384

385

386

387

388

389

390

391

392

393

394

395

396

397

398

399

400

401

402

403

404

405

406

407

408

409

410

411

Canter, P.H., Thomas, H., Ernst, E., 2005. Bringing medicinal plants into cultivation: opportunities and challenges for biotechnology. Trends in Biotechnology 23, 180-185. https://doi.org/10.1016/j.tibtech.2005.02.002

Chase, B.M., Meadows, M.E., 2007. Late Quaternary dynamics of southern Africa's winter rainfall zone. Earth-Science Reviews 84, 103-138.

https://doi.org/10.1016/j.earscirev.2007.06.002

Coates, D.J., Byrne, M., Moritz, C., 2018. Genetic diversity and conservation units: dealing with the species-population continuum in the age of genomics. Frontiers in Ecology and Evolution 6. https://doi.org/10.3389/fevo.2018.00165

Cowan, O.S., Anderson, P.M.L., 2014. The peninsula shale renosterveld of Devils Peak, Western Cape: A study into the vegetation and seedbank with a view toward potential restoration. South African Journal of Botany 95, 135-145.

https://doi.org/10.1016/j.sajb.2014.09.003

Cowling, R.M., Bradshaw, P.L., Colville, J.F., Forest, F., 2017. Levyns law: explaining the evolution of a remarkable longitudinal gradient in Cape plant diversity. Transactions of the Royal Society of South Africa 72, 184-201.

https://doi.org/10.1080/0035919x.2016.1274277

Cowling, R.M., Heijnis, C.E., 2001. The identification of Broad Habitat Units as biodiversity entities for systematic conservation planning in the Cape Floristic Region. South African Journal of Botany 67, 15-38. https://doi.org/10.1016/s0254-6299(15)31087-5

Cowling, R.M., Lombard, A.T., 2002. Heterogeneity, speciation/extinction history and climate: explaining regional plant diversity patterns in the Cape Floristic Region. Diversity and Distributions 8, 163-179. https://doi.org/10.1046/j.1472-4642.2002.00143.x

Cowling, R.M., Potts, A.J., Bradshaw, P.L., Colville, J., Arianoutsou, M., Ferrier, S., Forest, F., Fyllas, N.M., Hopper, S.D., Ojeda, F., Procheş, Ş., Smith, R.J., Rundel, P.W., Vassilakis, E., Zutta, B.R., 2015. Variation in plant diversity in mediterranean-climate ecosystems: the role of climatic and topographical stability. Journal of Biogeography 42, 552-564.

https://doi.org/10.1111/jbi.12429

Peer) reviewing PDF | (2020:06:50423:1:0:NEW 26 Aug 2020) 
412 Cowling, R.M., Pressey, R.L., Rouget, M., Lombard, A.T., 2003. A conservation plan for a 413 global biodiversity hotspot - the Cape Floristic Region, South Africa. Biological

414 Conservation 112, 191-216. https://doi.org/10.1016/s0006-3207(02)00425-1

415 Cowling, R.M., Procheș, Ş., Partridge, T.C., 2009. Explaining the uniqueness of the Cape flora: 416 Incorporating geomorphic evolution as a factor for explaining its diversification. Molecular 417 Phylogenetics and Evolution 51, 64-74. https://doi.org/10.1016/j.ympev.2008.05.034

418 Edler, D., Guedes, T., Zizka, A., Rosvall, M., Antonelli, A., 2016. Infomap bioregions: 419 interactive mapping of biogeographical regions from species distributions. Systematic 420 Biology syw087. https://doi.org/10.1093/sysbio/syw087

421

422

423

424

425

426

427

428

429

430

431

432

433

434

435

436

437

438

439

440

441

442

443

444

Ellis, A.G., Verboom, G.A., van der Niet, T., Johnson, S.D., Linder, H.P., 2014. Speciation and extinction in the Greater Cape Floristic Region, in: Fynbos. Oxford University Press, pp. 119-141. https://doi.org/10.1093/acprof:oso/9780199679584.003.0006

Fraser, D.J., Bernatchez, L., 2001. Adaptive evolutionary conservation: towards a unified concept for defining conservation units. Molecular Ecology 10, 2741-2752. https://doi.org/10.1046/j.1365-294x.2001.t01-1-01411.x

Goldblatt, P., Manning, J.C., 2002. Plant diversity of the Cape Region of southern Africa. Annals of the Missouri Botanical Garden 89, 281. https://doi.org/10.2307/3298566

Heelemann, S., Daniels, F., Rebelo, A.G., Poschlod, P., Reisch, C., 2013. Conservation genetics of (silvertree) a flag ship species of the Cape peninsula. South African Journal of Botany 88, 361-366. https://doi.org/10.1016/j.sajb.2013.08.014

Helme, N.A., Trinder-Smith, T.H., 2006. The endemic flora of the Cape peninsula, South Africa. South African Journal of Botany 72, 205-210. https://doi.org/10.1016/j.sajb.2005.07.004

Hewitt, G.M., 2008. Speciation, hybrid zones and phylogeography - or seeing genes in space and time. Molecular Ecology 10, 537-549. https://doi.org/10.1046/j.1365-

294x.2001.01202.x

Hufford, K.M., Mazer, S.J., 2003. Plant ecotypes: genetic differentiation in the age of ecological restoration. Trends in Ecology \& Evolution 18, 147-155.

https://doi.org/10.1016/s0169-5347(03)00002-8

Huntley, B., Collingham, Y.C., Singarayer, J.S., Valdes, P.J., Barnard, P., Midgley, G.F., Altwegg, R., Ohlemuller, R., 2016. Explaining patterns of avian diversity and endemicity: climate and biomes of southern Africa over the last 140,000 years. Journal of Biogeography 43, 874886. https://doi.org/10.1111/jbi.12714 
445 Johnson, S.D., 2018. Natural hybridization in the orchid flora of South Africa: comparisons 446 among genera and floristic regions. South African Journal of Botany 118, 290-298.

447 https://doi.org/10.1016/j.sajb.2018.01.011

448 Lacaze, B., Dudek, J., and Picard, J. (2018). “GRASS GIS Software with QGIS," in QGIS and 449 Generic Tools, John Wiley \& Sons, Inc., New Jersey, 67-106.

450 doi:10.1002/9781119457091.ch3.

451 Laikre, L., Schwartz, M.K., Waples, R.S., Ryman, N., 2010. Compromising genetic diversity in 452 the wild: unmonitored large-scale release of plants and animals. Trends in Ecology \& 453 Evolution 25, 520-529. https://doi.org/10.1016/j.tree.2010.06.013

454 455

456

457

458

459

460

461

462

463

464

465

466

467

468

469

470

471

472

473

474

475

476

477

Latimer, A.M., Silander, J.A., Rebelo, A.G., Midgley, G.F., 2009. Experimental biogeography: the role of environmental gradients in high geographic diversity in Cape Proteaceae. Oecologia 160, 151-162. https://doi.org/10.1007/s00442-009-1275-3

Lexer, C., Mangili, S., Bossolini, E., Forest, F., Stölting, K.N., Pearman, P.B., Zimmermann, N.E., Salamin, N., 2013. 'Next generation' biogeography: towards understanding the drivers of species diversification and persistence. Journal of Biogeography 40, 1013-1022. https://doi.org/10.1111/jbi.12076

Lexer, C., Wuest, R.O., Mangili, S., Heuertz, M., Stolting, K.N., Pearman, P.B., Forest, F., Salamin, N., Zimmermann, N.E., Bossolini, E., 2014. Genomics of the divergence continuum in an African plant biodiversity hotspot, I: drivers of population divergence in Restio capensis (Restionaceae). Molecular Ecology 23, 4373-4386.

https://doi.org/10.1111/mec.12870

Linder, H.P., 2003. The radiation of the Cape flora, southern Africa. Biological Reviews 78, 597-638. https://doi.org/10.1017/s1464793103006171

Lubbe, A., Verpoorte, R., 2011. Cultivation of medicinal and aromatic plants for specialty industrial materials. Industrial Crops and Products 34, 785-801. https://doi.org/10.1016/j.indcrop.2011.01.019

Macqueen, T.P., Potts, A.J., 2018. Re-opening the case of Frankenflora: evidence of hybridisation between local and introduced Protea species at Van Stadens Wildflower Reserve. South African Journal of Botany 118, 315-320.

https://doi.org/10.1016/j.sajb.2018.03.018

Malgas, R.R., Potts, A.J., Oettlé, N.M., Koelle, B., Todd, S.W., Verboom, G.A., Hoffman, M.T., 2010. Distribution, quantitative morphological variation and preliminary molecular analysis of different growth forms of wild rooibos (Aspalathus linearis) in the northern 
478 Cederberg and on the Bokkeveld Plateau. South African Journal of Botany 76, 72-81.

479 https://doi.org/10.1016/j.sajb.2009.07.004

480 Mayonde, S.G., Cron, G.V., Gaskin, J.F., Byrne, M.J., 2015. Evidence of Tamarix hybrids in 481 South Africa, as inferred by nuclear ITS and plastid trnStrnG DNA sequences. South African 482 Journal of Botany 96, 122-131. https://doi.org/10.1016/j.sajb.2014.10.011

483

484

485

486

487

488

489

490

491

492

493

494

495

496

497

498

499

500

501

502

503

504

505

506

507

508

509

510

511

McDonald, D.J., Cowling, R.M., 1995. Towards a profile of an endemic mountain fynbos flora: Implications for conservation. Biological Conservation 72, 1-12. https://doi.org/10.1016/0006-3207(94)00030-t

McKay, J.K., Christian, C.E., Harrison, S., Rice, K.J., 2005. How Local Is Local?-A review of practical and conceptual issues in the genetics of restoration. Restoration Ecology 13, 432440. https://doi.org/10.1111/j.1526-100x.2005.00058.x

Milton, S.J., Bond, W.J., Du Plessis, M.A., Gibbs, D., Hilton-Taylor, C., Linder, H.P., Raitt, L., Wood, J., Donaldson, J.S., 1999. A protocol for plant conservation by translocation in threatened lowland fynbos. Conservation Biology 13, 735-743.

https://doi.org/10.1046/j.1523-1739.1999.98306.x

Morando, M., Avila, L.J., Sites, J.W., 2003. Sampling strategies for delimiting species: genes, individuals, and populations in the Liolaemus elongatus-kriegi complex (Squamata: Liolaemidae) in Andean - Patagonian South America. Systematic Biology 52, 159-185. https://doi.org/10.1080/10635150390192717

Médail, F., Baumel, A., 2018. Using phylogeography to define conservation priorities: The case of narrow endemic plants in the Mediterranean Basin hotspot. Biological Conservation 224, 258-266. https://doi.org/10.1016/j.biocon.2018.05.028

Ojeda, F., Budde, K.B., Heuertz, M., Segarra-Moragues, J.G., González-Martínez, S.C., 2015. Biogeography and evolution of seeder and resprouter forms of Erica coccinea (Ericaceae) in the fire-prone Cape fynbos. Plant Ecology 217, 751-761. https://doi.org/10.1007/s11258015-0539-8

Pirie, M.D., Oliver, E.G.H., Gehrke, B., Heringer, L., Mugrabi de Kuppler, A., Le Maitre, N.C., Bellstedt, D.U., 2017. Underestimated regional species diversity in the Cape Floristic Region revealed by phylogenetic analysis of the Erica abietina/E. viscaria clade (Ericaceae). Botanical Journal of the Linnean Society 184, 185-203. https://doi.org/10.1093/botlinnean/box021

Potts, A.J., 2017. Genetic risk and the transition to cultivation in Cape endemic crops - The example of honeybush (Cyclopia)?. South African Journal of Botany 110, 52-56.

https://doi.org/10.1016/j.sajb.2016.09.004 
512 Potts, A. J., Hedderson, T. A., Vlok, J. H. J., and Cowling, R. M. (2013). Pleistocene range 513 dynamics in the eastern Greater Cape Floristic Region: A case study of the Little Karoo 514 endemic Berkheya cuneata (Asteraceae). South African Journal of Botany 88, 401-413. 515 doi:10.1016/j.sajb.2013.08.009.

516 Pressey, R.L., Cowling, R.M., Rouget, M., 2003. Formulating conservation targets for 517 biodiversity pattern and process in the Cape Floristic Region, South Africa. Biological 518 Conservation 112, 99-127. https://doi.org/10.1016/s0006-3207(02)00424-x

519 Pressey, R.L., Johnson, I.R., Wilson, P.D., 1994. Shades of irreplaceability: towards a measure 520 of the contribution of sites to a reservation goal. Biodiversity and Conservation 3, 242-262. 521 https://doi.org/10.1007/bf00055941

522 Prunier, R., Akman, M., Kremer, C.T., Aitken, N., Chuah, A., Borevitz, J., Holsinger, K.E., 2017. 523 Isolation by distance and isolation by environment contribute to population differentiation 524 in Protea repens (Proteaceae L.), a widespread South African species. American Journal of 525 Botany 104, 674-684. https://doi.org/10.3732/ajb.1600232

526

527

528

529

530

531

532

533

534

535

536

537

538

539

540

541 542 543

Prunier, R., Holsinger, K.E., 2010. Was it an explosion? Using population genetics to explore the dynamics of a recent radiation within Protea (Proteaceae L.). Molecular Ecology 19, 3968-3980. https://doi.org/10.1111/j.1365-294x.2010.04779.x

Rebelo, A.G., Holmes, P.M., Dorse, C., Wood, J., 2011. Impacts of urbanization in a biodiversity hotspot: Conservation challenges in Metropolitan Cape Town. South African Journal of Botany 77, 20-35. https://doi.org/10.1016/j.sajb.2010.04.006

Rosauer, D.F., Blom, M.P.K., Bourke, G., Catalano, S., Donnellan, S., Gillespie, G., Mulder, E., Oliver, P.M., Potter, S., Pratt, R.C., Rabosky, D.L., Skipwith, P.L., Moritz, C., 2016. Phylogeography, hotspots and conservation priorities: an example from the top end of Australia. Biological Conservation 204, 83-93. https://doi.org/10.1016/j.biocon.2016.05.002

Rouget, M., Cowling, R.M., Pressey, R.L., Richardson, D.M., 2003. Identifying spatial components of ecological and evolutionary processes for regional conservation planning in the Cape Floristic Region, South Africa. Diversity Distributions 9, 191-210. https://doi.org/10.1046/j.1472-4642.2003.00025.x

Schipmann, U., Leaman, D.J., Cunningham, A.B., Walter, S., 2005. Impact of cultivation and collection on the conservation of medicinal plants: Global trends and issues. Acta Horticulturae 31-44. https://doi.org/10.17660/actahortic.2005.676.3 
544 Schutte, A.L., Vlok, J.H.J., Van Wyk, B.E., 1995. Fire-survival strategy - a character of 545 taxonomic, ecological and evolutionary importance in fynbos legumes. Plant Systematics 546 and Evolution 195, 243-259. https://doi.org/10.1007/bf00989299

547 Soltis, D.E., Morris, A.B., Mclachlan, J.S., Manos, P.S., Soltis, P.S., 2006. Comparative 548 phylogeography of unglaciated eastern North America. Molecular Ecology 15, 4261-4293. 549 https://doi.org/10.1111/j.1365-294x.2006.03061.x

550 Sork, V.L., Gugger, P.F., Chen, J.M., Werth, S., 2016. Evolutionary lessons from California 551 plant phylogeography. Proceedings of the National Academy of Sciences 113, 8064-8071. 552 https://doi.org/10.1073/pnas.1602675113

553 554

555

556

557

558

559

560

561

562

563

564

565

566

567 568

569

570

571

572

573

574

575

576

Stapledon, R.G., 1928. Cocksfoot grass (Dactylis.): Ecotypes in relation to the biotic factor. The Journal of Ecology 16, 71. https://doi.org/10.2307/2255843

Tansley, S.A., Brown, C.R., 2000. RAPD variation in the rare and endangered Leucadendron elimense (Proteaceae): implications for their conservation. Biological Conservation 95, 3948. https://doi.org/10.1016/s0006-3207(00)00015-x

Thakur, M., Schättin, E.W., McShea, W.J., 2018. Globally common, locally rare: revisiting disregarded genetic diversity for conservation planning of widespread species. Biodiversity and Conservation 27, 3031-3035. https://doi.org/10.1007/s10531-018-1579-x

Tolley, K.A., Bowie, R.C.K., Measey, J.G., Price, B.W., Forest, F., 2014. The shifting landscape of genes since the Pliocene: Terrestrial phylogeography in the Greater Cape Floristic Region, in: Fynbos. Oxford University Press, pp. 142-163.

https://doi.org/10.1093/acprof:oso/9780199679584.003.0007

Turesson, G., 2010. The genotypical response of the plant species to the habitat. Hereditas 3, 211-350. https://doi.org/10.1111/j.1601-5223.1922.tb02734.x

Vance, B.D., Kucera, C.L., 1960. Flowering variations in Eupatorium . Ecology 41, 340-345. https://doi.org/10.2307/1930225

Waller, P.A., Anderson, P.M., Holmes, P.M., Newton, R.J., 2015. Developing a species selection index for seed-based ecological restoration in peninsula shale renosterveld, Cape Town. South African Journal of Botany 99, 62-68. https://doi.org/10.1016/j.sajb.2015.03.189

Waller, P.A., Anderson, P.M.L., Holmes, P.M., Allsopp, N., 2016. Seedling recruitment responses to interventions in seed-based ecological restoration of peninsula shale renosterveld, Cape Town. South African Journal of Botany 103, 193-209. https://doi.org/10.1016/j.sajb.2015.09.009 
577 Weimarck, H., 1941. Phytogeographical groups, centres and intervals within the Cape flora. 578 Acta Universita- Tis Lundensis, Nova Series, Sectio 2, Medica, Mathematica, Scientiae 579 Rerum Naturalium 37, 3-143.

580 Caujapé-Castells, J., Jansen, R.K., Pedrola-Monfort, J., Membrives, N., 2002. Space-time 581 diversification of Androcymbium Willd. (Colchicaceae) in western South Africa. Plant 582 Systematics and Evolution 232, 73-88. https://doi.org/10.1007/s006060200028

583 Da Silva, M.N.F., Patton, J.L., 1998. Molecular phylogeography and the evolution and 584 585 conservation of Amazonian mammals. Molecular Ecology 7, 475-486. https://doi.org/10.1046/j.1365-294x.1998.00276.x

588

Gutiérrez-García, T.A., Vázquez-Domínguez, E., 2011. Comparative phylogeography: Designing studies while surviving the process. BioScience 61, 857-868. https://doi.org/10.1525/bio.2011.61.11.5

589

590

591

592

593

594

595

596

597

598

599

600

601

602

603
Segarra-Moragues, J.G., Ojeda, F., 2010. Postfire response and genetic diversity in Erica coccinea: connecting population dynamics and diversification in a biodiversity hotspot. Evolution 64, 3511-3524. https://doi.org/10.1111/j.1558-5646.2010.01064.x

Treurnicht M, Colville JF, Joppa LN, Huyser O, Manning J. 2017. Counting complete? Finalising the plant inventory of a global biodiversity hotspot. Peer] 5:e2984 https://doi.org/10.7717/peerj.2984

Trinder-Smith, H., Cowling, R.M., Linder, H.P., 1996. Profiling a besieged flora: endemic and threatened plants of the Cape peninsula, South Africa. Biodiversity and Conservation 5, 575-589. https://doi.org/10.1007/bf00137610

Turchetto-Zolet, A.C., Pinheiro, F., Salgueiro, F., Palma-Silva, C., 2012. Phylogeographical patterns shed light on evolutionary process in South America. Molecular Ecology 22, 11931213. https://doi.org/10.1111/mec.12164

Van der Niet, T., Pirie, M.D., Shuttleworth, A., Johnson, S.D., Midgley, J.J., 2013. Do pollinator distributions underlie the evolution of pollination ecotypes in the Cape shrub Erica plukenetii?. Annals of Botany 113, 301-316. https://doi.org/10.1093/aob/mct193 


\section{Figure 1}

Distribution of Centres and sub-Centres of Endemism of Bradshaw et al. (2015) in relation to earlier phytogeographic zones (references given in image).

Phytogeographic zones are denoted by different line weights and colours following the description in the figure key. Each CoE, representing the co-distribution of CFR endemic plant species at a QDS resolution, is colourised and numbered on the map. The image is reproduced from Bradshaw et al. (2015) with the authors' permission.

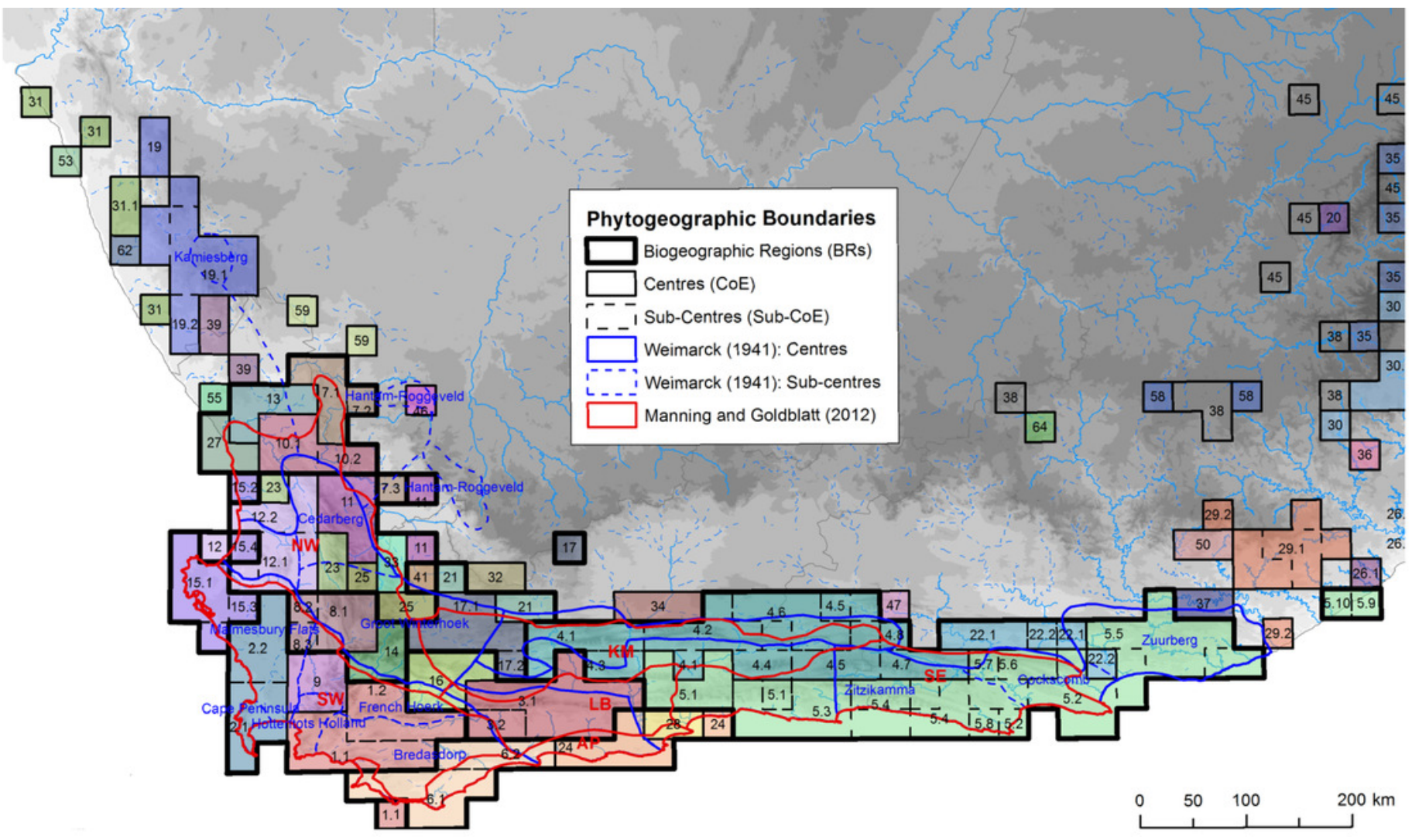




\section{Figure 2}

Sample distributions for five of the phylogeographic studies used to test for phylogeographic breaks across Centres of Endemism.
A) Protea repens (L.) L., Prunier et al., 2017; B) Cyclopia genistoides (L) R.Br. (diamonds) and
C. subternata Vogel (circles), Galuszynski and Potts, 2020b; C) Tetraria triangularis (Boeck.)
C. B.Clarke, Britton et al., 2014; D) Leucospermum tottum (L.) R. Br., Johnson et al., 2014; E)
Erica abietina L., Pirie et al., 2017. Circle colours represent genetic groups (as determined from the original phylogeographic analysis from the population's source study), outline colour represent the population scorings used; red indicates populations that exhibit inter-CoE phylogeographic homogeneity, orange outlines indicate populations marked as having uncertain CoE membership, green outlines indicate intra-CoE genetic variation, and white outlines represent cases of inter-CoE phylogeographic breaks. 

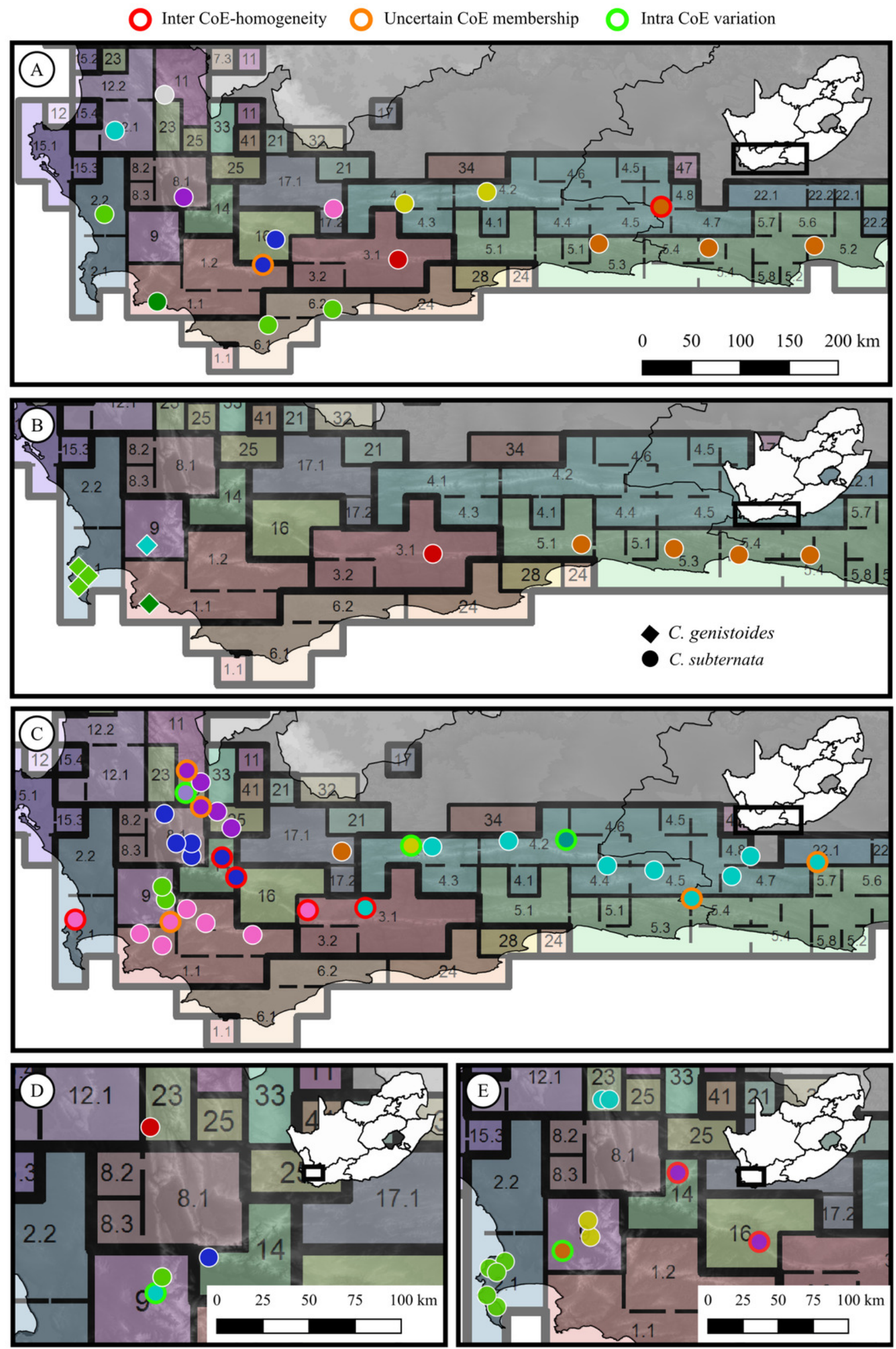

Peer) reviewing PDF | (2020:06:50423:1:0:NEW 26 Aug 2020) 


\section{Figure 3}

Main figure, counts of the three population pair scoring options across $33 \mathrm{CoE}$ boundaries. Inset (bottom right), counts of population pairs exhibiting either intra-CoE genetic variation or not.

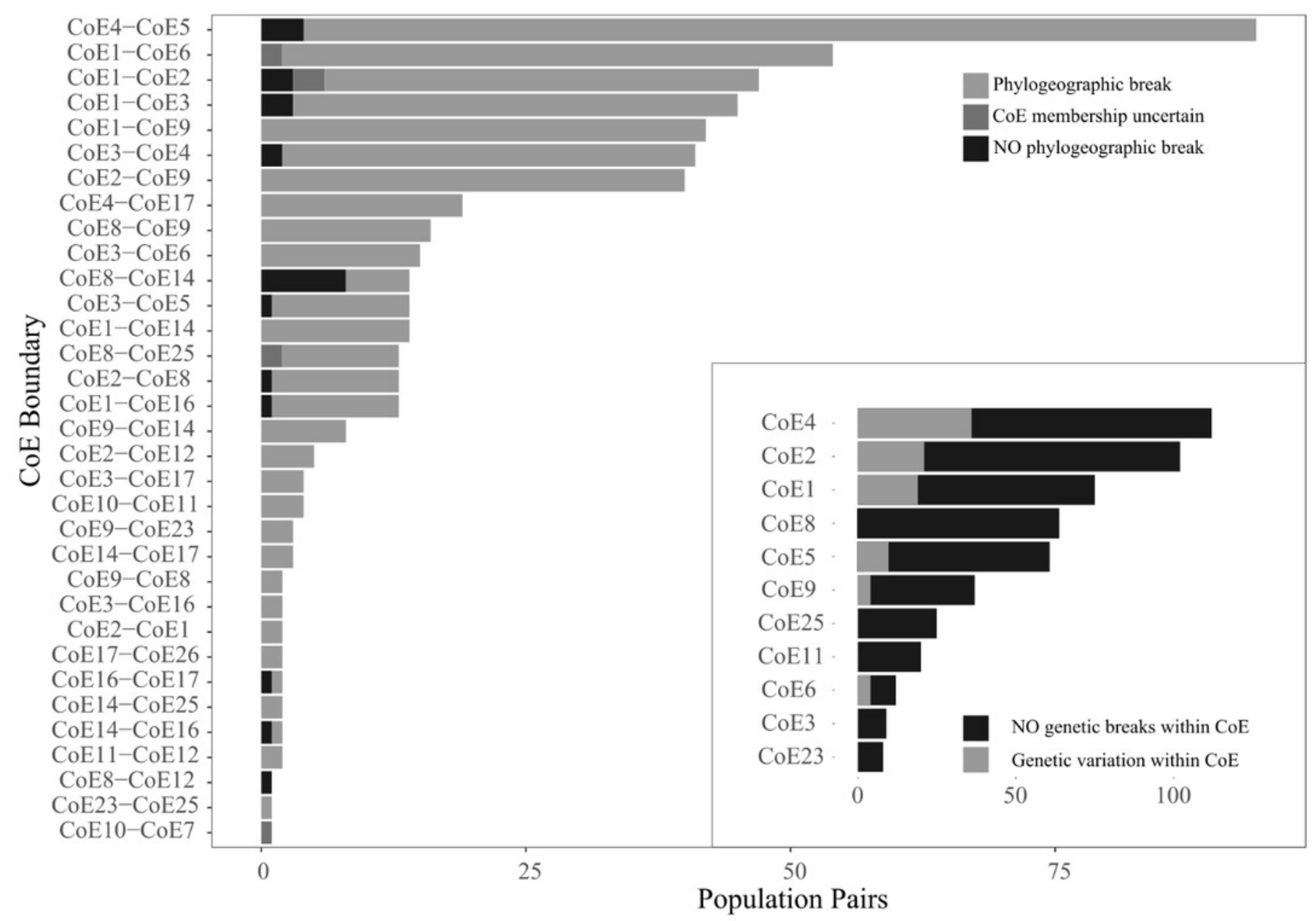




\section{Table $\mathbf{1}$ (on next page)}

Summary of the results from the 12 data sets used to test for phylogeographic breaks across the boundaries between Centres of Endemism in the Cape Floristic Region, South Africa. 


\begin{tabular}{|c|c|c|c|c|c|c|c|c|c|c|c|c|c|c|c|}
\hline Genus & \begin{tabular}{|l} 
Family \\
\end{tabular} & \begin{tabular}{|l|l} 
No. species \\
investigated \\
(populations)
\end{tabular} & \begin{tabular}{|l} 
CFR \\
region
\end{tabular} & \begin{tabular}{|l|}
$\substack{\text { Min samples } \\
\text { per } \\
\text { population }}$ \\
\end{tabular} & \begin{tabular}{|l|}
$\begin{array}{l}\text { Max samples } \\
\text { per } \\
\text { population }\end{array}$ \\
\end{tabular} & 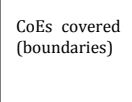 & $\begin{array}{l}\text { cenetic break } \\
\text { across } \\
\text { (\%) Colss }\end{array}$ & $\begin{array}{l}\text { Uncertain } \\
\text { CoE } \\
\text { membership } \\
\text { (\%) }\end{array}$ & 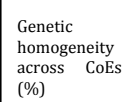 & 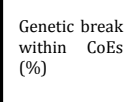 & $\begin{array}{l}\text { Primary seed } \\
\text { dispersal } \\
\text { mechanism }\end{array}$ & \begin{tabular}{|l} 
Primary \\
pollen \\
dispersal \\
meranism
\end{tabular} & $\begin{array}{l}\text { Molecular } \\
\text { methods used }\end{array}$ & \begin{tabular}{|l|}
$\begin{array}{c}\text { Cenome } \\
\text { explored }\end{array}$ \\
\end{tabular} & \begin{tabular}{|l} 
Reference \\
\end{tabular} \\
\hline Aspalathus & Fabaceae & $1(5)$ & w & 3 & 5 & $2(2)$ & 100 & 0 & 0 & 0 & Myrmecochory & Insect & \begin{tabular}{|l} 
Sanger \\
sequencing
\end{tabular} & Chloroplast & \begin{tabular}{|l|} 
Malasas, et al. \\
2010
\end{tabular} \\
\hline cyclopia & Fabaceae & $1(3)$ & E & 24 & 30 & $1(2)$ & 100 & 0 & 0 & 0 & Myrmecochory & Insect & Microsatellite & \begin{tabular}{|l|} 
Nuclear \\
\end{tabular} & $\begin{array}{l}\begin{array}{l}\text { Niemand, } \\
\text { al, } 2018\end{array} \\
\text { et }\end{array}$ \\
\hline cyclopia & \begin{tabular}{|l|} 
Fabaceae \\
\end{tabular} & $3(22)$ & W\&E & 6 & 24 & $5(5)$ & 100 & 0 & 0 & 3 & Myrmecochory & Insect & \begin{tabular}{|l|l} 
Sanger \\
sequencing
\end{tabular} & Chloroplast & \begin{tabular}{|l} 
Galussynski \\
and \\
20200tsa, 20200
\end{tabular} \\
\hline Erica & Ericaceae & 1 (21) & w & 10 & 30 & $2(6)$ & 86 & 5 & 9 & 30 & Myrmecochory & Insect & Microsatellite & \begin{tabular}{|l|} 
Nuclear \\
\end{tabular} & \begin{tabular}{|l|l}
$\begin{array}{l}\text { Segarra- } \\
\text { Moragues } \\
\text { Ojeda, 2010 }\end{array}$ \\
\&
\end{tabular} \\
\hline Erica & \begin{tabular}{|l|} 
Ericaceae \\
\end{tabular} & $1(14)$ & w & 1 & 2 & $4(5)$ & 93 & 7 & 0 & 15 & Passive & Bird & \begin{tabular}{|l} 
Sanger \\
sequencing
\end{tabular} & $\begin{array}{l}\begin{array}{l}\text { Nuclear and } \\
\text { Chloroplast }\end{array} \\
\text { cols }\end{array}$ & \begin{tabular}{|l}
$\begin{array}{l}\text { Pirie, et al. } \\
2017\end{array}$ \\
201
\end{tabular} \\
\hline Gladiolus & \begin{tabular}{|l} 
Iridaceae \\
\end{tabular} & $1(15)$ & w & 4 & 11 & $4(6)$ & 81 & 6 & 13 & 37 & Wind & Insect & \begin{tabular}{|l} 
Sanger \\
sequencing \\
and AFLP
\end{tabular} & $\begin{array}{l}\text { Nuclear and } \\
\text { Chloroplast }\end{array}$ & \begin{tabular}{|l} 
Rymer, et al. \\
2010
\end{tabular} \\
\hline $\begin{array}{l}\text { Leucospermu } \\
m\end{array}$ & Proteaceae & 1 (4) & w & 7 & 22 & $2(2)$ & 100 & 0 & 0 & 12 & Serotinous & Bird & $\begin{array}{l}\text { Sanger } \\
\text { sequencing }\end{array}$ & 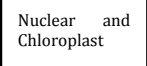 & \begin{tabular}{|l|} 
Johnson, et al. \\
2014
\end{tabular} \\
\hline Protea & Proteaceae & $6(30)$ & W\&E & 20 & 20 & $7(10)$ & 87 & 3 & 10 & 23 & Wind & Bird & Microsatellite & Nuclear & \begin{tabular}{|l}
$\begin{array}{l}\text { Prunier } \\
\text { Holosinger, } \\
2010\end{array}$ \\
20
\end{tabular} \\
\hline Protea & Proteaceae & $1(19)$ & W\&E & 8 & 73 & 6(11) & 71 & 7 & 22 & 10 & Wind & Bird & $\begin{array}{l}\begin{array}{l}\text { Next-Gen } \\
\text { sequencing }\end{array} \\
\end{array}$ & \begin{tabular}{|l|} 
Nuclear \\
\end{tabular} & \begin{tabular}{|l|}
$\begin{array}{l}\text { Prunier, et al. } \\
2017\end{array}$ \\
\end{tabular} \\
\hline Restio & \begin{tabular}{|l} 
Restionaceae \\
\end{tabular} & $1(10)$ & W\&E & 5 & 10 & $5(6)$ & 100 & 0 & 0 & 0 & Wind & Wind & \begin{tabular}{|l|} 
Next-Gen and \\
Sanger ar \\
sequencing
\end{tabular} & \begin{tabular}{|l}
$\begin{array}{l}\text { Nuclear } \\
\text { Chloroplast }\end{array}$ \\
Cast
\end{tabular} & \begin{tabular}{|l} 
Lexer, et al. \\
2014
\end{tabular} \\
\hline Tetrara & cyperaceae & $1(36)$ & W\&E & 2 & 24 & $7(10)$ & 75 & 19 & 6 & 14 & Passive & Wind & \begin{tabular}{|l} 
Sanger \\
sequencing
\end{tabular} & $\begin{array}{l}\begin{array}{l}\text { Nuclear and } \\
\text { Chloroplast }\end{array} \\
\text { col }\end{array}$ & \begin{tabular}{|l} 
Britton, et al. \\
2014
\end{tabular} \\
\hline
\end{tabular}

